\title{
Social capital elite, excluded participators, busy working parents and aging, participating less: types of community participators and their mental health
}

Received: 26 September 2007 / Accepted: 15 February 2008 / Published online: 22 March 2008

Abstract With the prevalence and costs of mental health problems increasing, safe, effective and economically viable prevention and treatment strategies are urgently needed. Community participation is protectively linked to mental health and is considered a valid mental health promotion strategy. However, little consideration has been given to socio-demographically driven patterns of participation that would differentially affect the success of such a strategy. The aims of this study were to group and describe members of a socioeconomically disadvantaged rural region according to patterns of community participation, report on their levels of social cohesion and psychological distress and reflect on policy implications. Participants were 963 community members, aged 19-97, randomly selected from a socio-economically disadvantaged coastal Australian region, who voluntarily completed an anonymous postal survey. Measures included (1) frequency of fourteen types of participation, (2) thoughts and feelings about each type, and (3) five aspects of social cohesion. Two-step cluster analysis was undertaken to derive groupings of respondents based on their socio-demographic characteristics and levels of and perceptions about their participation. Psychological distress was assessed for each group. Four distinct groupings of participants were identified: social capital elite; busy working parents; aging, participating less; and excluded participators. The last of these reported particularly poor participation, cohesion and psychological distress. For mental health promotion strategies to be effective, they must be tailored to the circumstances of intended recipients. This requires a sophisticated analysis of target groups. This study has shown that

\footnotetext{
Dr. H. L. Berry, MA, BSc, BAppPsych, PhD ( $\square)$

National Centre for Epidemiology and Population Health

ANU College of Medicine and Health Sciences

Australian National University

Acton (ACT) 0200, Australia

Tel.: +61-2/6125-0394

Fax: +61-2/6125-0704

E-Mail: helen.berry@anu.edu.au
}

members of a socio-economically disadvantaged rural region may be described according to systematically varying patterns of socio-demographic characteristics, participation, social cohesion and distress. Policymakers might consider (1) how and whether different groups might respond to the use of increased community participation as a mental health promotion strategy and (2) barriers that might have to be overcome in different groups.

Key words mental health - community participation - social capital - vulnerable populations disadvantaged

In Australia, mental disorders accounted for $24 \%$ of non-fatal disease burden in 2003, not counting dementia, while suicide and self-harm accounted for $5.4 \%$ of fatal disease burden among men [6]. With levels of psychiatric morbidity likely to continue increasing [45], effective and economically viable prevention and treatment strategies are urgently needed. A growing body of prospective and crosssectional evidence demonstrates the benefits of community participation for preventing or delaying the onset of a wide range of child and adult mental health problems, and for ameliorating the course of and recovery from these problems $[2,17,18,29,39,44$, 46].

People participate (or not) in their communities in many ways [5]. These include "informal social connectedness", involving contact with family, friends and neighbours, [23, 33, 41], "civic engagement", including volunteering and joining community groups, [31, 40, 50, 52] and "political participation", including local activism and political protest $[35,43$, 47]. Fourteen separate types of community participation have been identified, of which seven (which Berry et al. [9] call the "Big 7") were associated with less psychological distress (contact with immediate household, extended family, friends, and neighbours; organised community activities; religious observance; 
and active interest in current affairs). Though associations between distress and the Big 7 types of participation individually were weak, there was a strong relationship between distress and breadth of participation across all the Big 7.

Community participation is part of and a prerequisite for the development of social capital, aspects of which are associated worldwide with better health (for a recent critical review of social capital and self-rated health worldwide, see [34]), including mental health [2]. Robert Putnam's conceptualisation of social capital, defined as a combination of community participation and the social cohesion it creates (2000: p.21), is used in this study because it dominates current debate [20], particularly with respect to health research [37]. Participation is also known as the structural component of social capital and cohesion as the cognitive component $[2,36,55]$, respectively "what people do" and "what people feel" [22]. Social capital can also be considered in terms of its purpose and the level at which connections are made within and between communities, with particular reference to power relationships (for a review, see [55]).

Raising levels of community participation-and, thereby, of social capital-is a commonly advocated mental health promotion strategy (e.g., [25]) and may be especially valuable for rural and remote locations, where high levels of disadvantage and limited access to clinical services are common $[3,19,26,38,56]$. But with mental health problems (and access to different levels and types of participation) unevenly distributed across different population groups [5], if participation is to be an effective mental health promotion strategy, appropriate forms of participation must be promoted, [9], accurately targeted [32, 54], and tailored to the characteristics of different groups. An understanding of how different types of people participate in their communities, or do not, is essential for effective targeting.

The aims of this study were to (1) explore whether residents of a socio-economically disadvantaged rural Australian region could be grouped according to their patterns of community participation, (2) prepare descriptive profiles of these groupings, (3) report on differences in social cohesion and psychological distress between groupings, and (4) comment on the policy implications of the groupings.

\section{Method}

\section{Participants and sampling procedure}

This study was conducted using data from the Eurobodalla Study [10], a cross-sectional study of "personal social capital" [7] and mental health in a socio-economically disadvantaged rural location. Data were collected from 963 residents of the Eurobodalla Shire in southern coastal New South Wales, Australia, aged 1997 years, randomly drawn from the electoral roll for the federal seat of Eden-Monaro. In Australia, where registration as a voter is compulsory for citizens, electoral rolls are an accepted source for general population sampling. A stratified sampling procedure was employed to recruit equal numbers of women $(N=500,51.9 \%)$ and men $(N=463,48.1 \%)$ and of different age-groups. The adjusted response rate was $30.1 \%$ and study participants were broadly representative of adults in the study region [10]. Approval to conduct this study was given by the Human Research Ethics Committee of The Australian National University (Protocol 2001/35). Analyses were performed using SPSS 15.0 for Windows (Statistical Package for Social Sciences, SPSS Inc.).

\section{Measures}

Community participation

Community participation was measured using the Australian Community Participation Questionnaire [9]. It measures frequency of fourteen types of participation: contact with immediate household, extended family, friends and neighbours; socialising with workmates; organised community activities; giving money to charity; voluntary sector activity; adult learning; religious observance; active interest in current affairs; expressing opinions publicly; community activism; and political protest. Each type of participation was measured with multiple items tapping participatory initiative, effort, and personal involvement, and was scored from 1 "rarely or never" to 7 "always or nearly always". Mean scores for each type of participation were calculated using weightings derived from one-factor congeneric models. All but one scale (Cronbach $\alpha$, hereafter " $\alpha$ ", $=0.64$ ) exhibited satisfactory internal consistency $(\alpha$ range $=0.72-0.96)$. All fourteen types of participation were included in the present study, as was an index of breadth of participation across the Big 7 [9].

Perceptions about participation-whether respondents thought they participated too little or too much in each type of participation, and whether they enjoyed each type of participation or not-were also measured. As for frequency of participation, perceptions about the Big 7 types of participation were more strongly related to psychological distress than were all types taken together [10]. Four 8-point indices (range 0-7) were computed tapping perceptions of participating too much or too little in each of the Big 7 types of participation, and of enjoying or not enjoying each of them.

Sufficiency of participation: Respondents reported whether "the amount of time" they spent engaging in each of the fourteen types of participation was too much or too little. Items were scored on a five-point response format where $1=$ "much too much", 2 = "a bit too much", 3 = "about right", $4=$ ="a bit too little", and $5=$ "much too little". Responses for the "too little" measure were recoded to 2 = "much too little", $1=$ "a bit too little" and all other responses $=0$, such that scores could range from 0 to 2 for each type of participation. The same approach was used to create "too much" scores for each type of participation. Sample means were then calculated for too much and too little time spent on each type of participation and a score of 1 (on or above the mean; participating too little/much) or 0 (below the mean; not participating too little/much) assigned to each respondent. The dichotomous scores were summed to create indices of too little and too much participation (Cronbach $\alpha=0.43$ and 0.27 , respectively).

Enjoyment of participation: Respondents reported "how much you enjoy" the time spent in each type of participation. Items were scored on a five-point response format where $1=$ "very enjoyable", 2 = "enjoyable", 3 = "OK", 4 = "unenjoyable", 5 = "very unenjoyable". The same procedure that was used to derive the sufficiency indices was used to create indices of enjoying and of not enjoying community participation (Cronbach $\alpha=0.61$ and 0.44 respectively). 


\section{Psychological distress}

Mental health was assessed using the Kessler 10-item measure of general psychological distress (K10) which measures symptoms of non-specific psychological distress [4]. Each item was scored on a five-point scale from $1=$ "none of the time" to $5=$ "all of the time". Final summed scores had a possible range of 10-50 with higher scores indicating higher levels of distress. Scores in the present sample ranged from 10 to 44 . Australian mean (M) and median (Md) scores and morbidity rates have been reported for the K10 scale. They are, respectively, $M=14.2, M d=12$, with $68 \%$ of respondents scoring $<15$ (indicating little or no distress), $29 \%$ scoring 16-30 (moderate distress) and 3\% scoring $>30$ (severe distress) [30].

\section{Personal social cohesion}

Personal social cohesion was defined as respondents' altruistic values, sense of belonging, generalised reciprocity, social trust and optimism [22]. Altruistic values were measured using the nine-item universalism domain of Schwarz's ten universal values [48]. Each item was scored on an asymmetrical seven-point scale from $1=$ "I'm totally against this" to $7=$ "I'm totally for this". Mean scores and standard deviations $\left(S_{\mathrm{x}}\right)$ were calculated by averaging the items $\left(M=5.99, S_{\mathrm{x}}=0.80, \alpha=0.85\right)$. Final scores range from 1 to 7 , with higher scores representing greater acceptance of the altruistic values. Sense of belonging was measured using the ten-item sub-scale of the Interpersonal Support Evaluation List [15]. Items are scored $1=$ "yes" or $0=$ "no". Total summed scores for each sub-scale range between 0 and $10\left(M=8.13, S_{\mathrm{x}}=2.37, \alpha=0.82\right)$ with higher scores representing greater sense of belonging.

Generalised reciprocity was measured using the one-item measure from the World Values Survey [27]. The item as used was "generally speaking, would you say that, most of the time, people try to be helpful, or are they mostly looking out for themselves?" The item was scored 1 = "people try to be helpful", $0=$ "people are mostly looking out for themselves", so that higher scores mean greater sense of generalised reciprocity. Seventy-nine percent of respondents indicated that they believed most people try to be helpful. Cronbach's alpha cannot be computed for one-item measures.

Social trust was measured using the Organizational Trust Inventory (OTI) [16] and the one-item measure of trust from the World Values Survey [27]. The latter item is very commonly used in epidemiology and its form varies. The form used in the present study was "generally speaking, would you say that most people can be trusted, or that you can't be too careful in dealing with people?" The item was scored 1 = "most people can be trusted", $0=$ "you can't be too careful", so that higher scores mean greater trust. Sixty-six percent of respondents indicated that they believed most people could be trusted.

The OTI, developed for measuring trust in organisations, includes a short-form with twelve items that has been adapted for use in the general population $[7,8]$. Three four-item sub-scales tap separate dimensions of trust, defined as believing that most people: avoid taking excessive advantage of others; try to negotiate honestly; and try to honour their commitments. Items are scored on a seven-point scale from "definitely agree" to "definitely disagree". Final average scores for each sub-scale and for the full scale range between 1 and 7 with higher scores indicating higher levels of trust. The sub-scales and full scale exhibited a high degree of internal consistency ( $\alpha$ range $=0.77-0.90$ ). While the OTI is a superior measure of trust, both measures correlate with distress [8]. Onefactor congeneric modelling of the two scales together revealed that all three sub-scales of the OTI and the World Values Survey item loaded significantly on a single latent factor (social trust) from which a weighted composite was computed (range 1-7, $M=5.04$, $S_{\mathrm{x}}=0.98, \alpha=0.81,[10]$.

Optimism was measured using Scheier et al.'s (1994) ten-item questionnaire. It includes four filler items, which were not used. Instead, the six optimism items were interspersed among the trust items. Consistent with the trust measure, each optimism item was scored on a seven-point scale from "definitely agree" to "definitely disagree". Final average scores for the scale $\left(M=4.97, S_{\mathrm{x}}=1.01\right.$, $\alpha=0.78$.) range between 1 and 7 with higher scores indicating higher levels of optimism.

\section{Socio-demographic data}

Participants reported their sex, age, Indigenous Australian status, years of education, responsibility for dependent persons (under and over 18 years), being in paid work at least six hours per week, living alone, and having a government benefit health care card. This last is a proxy for poverty because, in Australia, access to health care cards is strictly means-tested.

\section{Statistical methods}

Whole of sample descriptive statistics were produced for all measures, with one-way analyses of variance used to compare mean scores by sex. Participation profiles were generated using cluster analysis (for a review, see [11], under embargo), an appropriate analytic method for profiling in studies in which mental health is a focus [1]. Cluster analysis is an umbrella term that applies to a family of related techniques. It is conceptually similar to exploratory factor analysis, except that it is based on closeness ("proximity") among respondents in a dataset rather than closeness (correlations) among variables. Clusters can be created top-down or bottom-up by progressively separating (divisive clustering) or co-locating (agglomerative clustering) dis/ similar respondents in the dataset.

Two-step clustering was used for the present study-a type of clustering developed to accommodate mixed continuous, ordinal and categorical variables and large datasets, as in the present study - with proximities calculated using log-likelihood distances based on standardised scores, as required for mixed type variables. The first step of a two-step cluster analysis involves locating respondents in multi-dimensional space relative to one another based on their scores on selected variables (in this case, measures of socio-demographic circumstances and community participation). Because certain characteristics tend to co-occur, this process generates approximate groupings, or "clusters", of respondents with similar characteristics. In the second step, a decision is made about how many clusters are present.

Different cluster solutions may be evaluated relative to one another to determine which is the most appropriate. The most important criteria for making this judgement were substantive-meaningfulness, scientific usefulness, and parsimony-addressing the qualitative rather than the quantitative validity of the cluster solution. Statistical criteria were also computed: Schwarz's Bayesian Criterion and Akaike's Information Criterion, indices of change in the agglomeration schedule. Agglomeration schedules measure the distance between clusters for different cluster solutions. They jump sharply when too many clusters have been created. To help interpret the agglomeration schedules, the ratios of change in the agglomeration schedules from step to step in the clustering process were calculated.

Chi-squared analyses and factorial analyses of variance were deployed to assess between-cluster differences in distributions of categorical variables, measures of participation, cohesion and distress scores. All factorial analyses of variance indicated that at least one cluster centroid was significantly higher than at least one other centroid $(d f(3), F$ range 9.39-269.63, $P<0.0001)$. Levene's test indicated some variables violated the homogeneity of variance assumption; Dunnett's T3 post hoc contrasts, which do not assume equal variance, were used.

\section{Results}

Whole of sample descriptive statistics for psychological distress, frequency of and perceptions about 
community participation and social cohesion are presented first. These are followed by the results of the cluster analysis and a description of the clusters in terms of participation, social cohesion and distress. Integrated cluster profiles follow and the results section ends with an evaluation of the adequacy of the cluster solution.

\section{Psychological distress}

Scores in the present sample $(M=18.19, M d=17$, $\left.S_{\mathrm{x}}=6.15\right)$ revealed higher levels of distress than the Australian norms and consequently higher morbidity rates $(33 \%, 62 \%$ and $5 \%$, respectively).

\section{Frequency of and perceptions about community participation}

Mean scores and standard deviations for fourteen types of participation, the breadth of participation index and the indices of sufficiency and enjoyment of participation are presented in Table 1. Levels of participation varied by sex and, substantially, by type of participation (Fig. 1). Respondents tended to report participating more often in the Big 7 types of participation than in other types, with women participating slightly more frequently than did men in most types of participation, including six of the Big 7. Most respondents reported participating too little in and enjoying at least one type of participation, while few reported participating too much or not enjoying any type of participation.

\section{Personal social cohesion}

Mean scores and standard deviations for measures of social cohesion are presented in Table 2; with distributions of scores highly negatively skewed, most people reported high levels of all measures of cohesion. Women $\left(M=6.10, S_{\mathrm{x}}=0.72\right)$ reported slightly higher acceptance of universalistic values than did men (men $\left.M=5.87, S_{\mathrm{x}}=.86 ; F=20.34, d f(1), P<0.0001\right)$, but not a significantly greater sense of belonging (women $M=8.24, \quad S_{\mathrm{x}}=2.36, \quad$ men $M=8.02, \quad S_{\mathrm{x}}=2.38$; $F=1.94, d f(1), P>0.05)$. Seventy-nine percent of participants agreed that "most people try to help". With $83 \%$ of women compared with $75 \%$ endorsing this item, women were significantly and substantially more likely to report a sense of reciprocity than were men $(F=8.07, d f(1), P<0.005)$.

Table 1 Cluster centroids and standard deviations for fourteen types of community participation, Big 7 Index of breadth of participation and four indices of perceptions (higher scores indicate higher levels of participation)

\begin{tabular}{|c|c|c|c|c|c|c|c|c|c|c|}
\hline & \multicolumn{2}{|c|}{$\begin{array}{l}\text { Cluster 1: Busy } \\
\text { working parents }\end{array}$} & \multicolumn{2}{|c|}{$\begin{array}{l}\text { Cluster 2: Social } \\
\text { capital elites }\end{array}$} & \multicolumn{2}{|c|}{$\begin{array}{l}\text { Cluster 3: Excluded } \\
\text { participators }\end{array}$} & \multicolumn{2}{|c|}{$\begin{array}{l}\text { Cluster 4: Aging, } \\
\text { participating less }\end{array}$} & \multicolumn{2}{|c|}{ Whole sample } \\
\hline & Mean & $S_{x}$ & Mean & $S_{x}$ & Mean & $S_{x}$ & Mean & $S_{x}$ & Mean & $S_{x}$ \\
\hline \multicolumn{11}{|l|}{ Types of participation } \\
\hline Contact with household members ${ }^{a}$ & $5.74^{* * * c}$ & 1.68 & 5.37 & 2.25 & $5.88^{* * * c}$ & 1.59 & $4.93^{\# \# \# d}$ & 2.60 & 5.46 & 2.11 \\
\hline Contact with extended family ${ }^{\mathrm{a}}$ & 4.08 & 1.29 & $4.45^{* c}$ & 1.30 & $3.61^{\# d}$ & 1.37 & 3.99 & 1.32 & 4.02 & 1.34 \\
\hline Contact with friends ${ }^{\mathrm{a}}$ & 4.31 & 1.30 & $5.24^{* * * c}$ & 1.07 & $3.98^{\# d}$ & 1.42 & 4.22 & 1.26 & 4.37 & 1.34 \\
\hline Contact with neighbours ${ }^{\mathrm{a}}$ & $3.31^{\# \# \# \mathrm{~d}}$ & 1.55 & $4.45^{* * c}$ & 1.44 & $3.19^{\# \# \# \mathrm{~d}}$ & 1.55 & 3.97 & 1.50 & 3.68 & 1.58 \\
\hline Social contact with workmates & $3.60^{* * * c}$ & 1.37 & $3.34^{\mathrm{e}}$ & 1.40 & 1.97 & 1.21 & $1.08^{\# \# \# d ~}$ & 0.28 & 2.22 & 1.52 \\
\hline Ongoing informal learning & 2.16 & 1.32 & $2.78^{* * *} \mathrm{C}$ & 1.45 & 2.01 & 1.21 & $1.50^{\# \# \# \mathrm{~d}}$ & 0.90 & 2.03 & 1.28 \\
\hline Religious observance ${ }^{\mathrm{a}}$ & 1.85 & 1.45 & $3.06^{* * * c}$ & 2.05 & 1.69 & 1.26 & 1.90 & 1.42 & 2.04 & 1.59 \\
\hline Organised community activities ${ }^{a}$ & 3.41 & 2.12 & $4.59^{* * * c}$ & 1.88 & $2.78^{\# \# d}$ & 1.84 & $2.85^{\# \# d}$ & 1.95 & 3.31 & 2.07 \\
\hline Voluntary sector activity & 2.42 & 1.60 & $4.37^{* * * c}$ & 1.94 & 2.09 & 1.34 & 2.14 & 1.44 & 2.60 & 1.76 \\
\hline Giving money to charity & 4.42 & 1.27 & $5.17^{* * * c}$ & 1.27 & 4.12 & 1.25 & 4.28 & 1.28 & 4.44 & 1.31 \\
\hline Active interest in current affairs ${ }^{a}$ & 5.42 & 1.13 & $6.19^{* * * c}$ & 0.75 & $4.94^{\# \# \# \mathrm{~d}}$ & 1.25 & 5.59 & 1.11 & 5.51 & 1.16 \\
\hline Expressing opinions publicly & 1.61 & 0.86 & $3.06^{* * * c}$ & 1.63 & 1.51 & 0.88 & 1.51 & 0.80 & 1.80 & 1.16 \\
\hline Community activism & 1.27 & 0.45 & $2.28^{* * * c}$ & 1.30 & $1.16^{\# \# \mathrm{~d}}$ & 0.32 & 1.16 & 0.29 & 1.38 & 0.75 \\
\hline Political protest & 1.77 & 1.00 & $2.52^{* * * c}$ & 1.39 & 1.48 & 0.75 & $1.31^{\# d}$ & 0.53 & 1.70 & 1.01 \\
\hline \multicolumn{11}{|l|}{ Indices (breadth and perceptions) } \\
\hline Big 7 Index (breadth) & 3.44 & 1.47 & $5.02^{* * * c}$ & 1.11 & $2.84^{\# \# \# \mathrm{~d}}$ & 1.52 & 3.48 & 1.58 & 3.60 & 1.61 \\
\hline Participates too much ${ }^{b}$ & 0.22 & 0.47 & $0.39^{* * * c, f}$ & 0.75 & 0.33 & 0.61 & $0.14^{\# \# \# \mathrm{~d}, \mathrm{~g}}$ & 0.40 & 0.24 & 0.54 \\
\hline Participates too little $\mathrm{b}^{\mathrm{b}}$ & 2.50 & 1.50 & $1.81^{\# \# \# \mathrm{~d}, \mathrm{~h}}$ & 1.43 & $2.69^{* * * c, i}$ & 1.35 & 2.12 & 1.53 & 2.31 & 1.50 \\
\hline Enjoys participating & 2.46 & 1.79 & $3.30^{* * * c}$ & 1.87 & $1.67^{\# \# \# d}$ & 1.57 & 2.36 & 1.68 & 2.42 & 1.80 \\
\hline Does not enjoy participating ${ }^{b}$ & 0.08 & 0.29 & 0.08 & 0.30 & $0.42^{* * * c}$ & 0.86 & 0.08 & 0.28 & 0.15 & 0.48 \\
\hline
\end{tabular}

${ }^{a}$ One of the Big 7 types of participation

${ }^{\mathrm{b}}$ Higher scores indicate negative perceptions (greater perception of too much or too little participation and of not enjoying participation)

CCluster centroid is significantly higher than the next highest centroid, ${ }^{*} P<0.05,{ }^{* *} P<0.01,{ }^{* * *} P<0.001$

${ }^{d}$ Cluster centroid is significantly lower than the next lowest centroid, ${ }^{\#} P<0.05,{ }^{\# \#} P<0.01,{ }^{\# \#} P<0.001$

${ }^{\mathrm{e} C e n t r o i d ~ m e a n ~ f o r ~ m e m b e r s ~ o f ~ c l u s t e r ~} 2$ who are in paid work; centroid does not differ significantly from cluster 1 centroid

fCluster centroid is significantly higher than that of cluster 4 only

${ }^{9}$ Cluster centroid is not significantly lower than that of cluster 1

${ }^{\mathrm{h}}$ Cluster centroid is not significantly lower than that of cluster 4

'Cluster centroid is not significantly higher than that of cluster 1 
Fig. 1 Mean levels of community participation, with the "Big 7" types of participation shown in darker shading (higher scores indicate higher levels of participation)

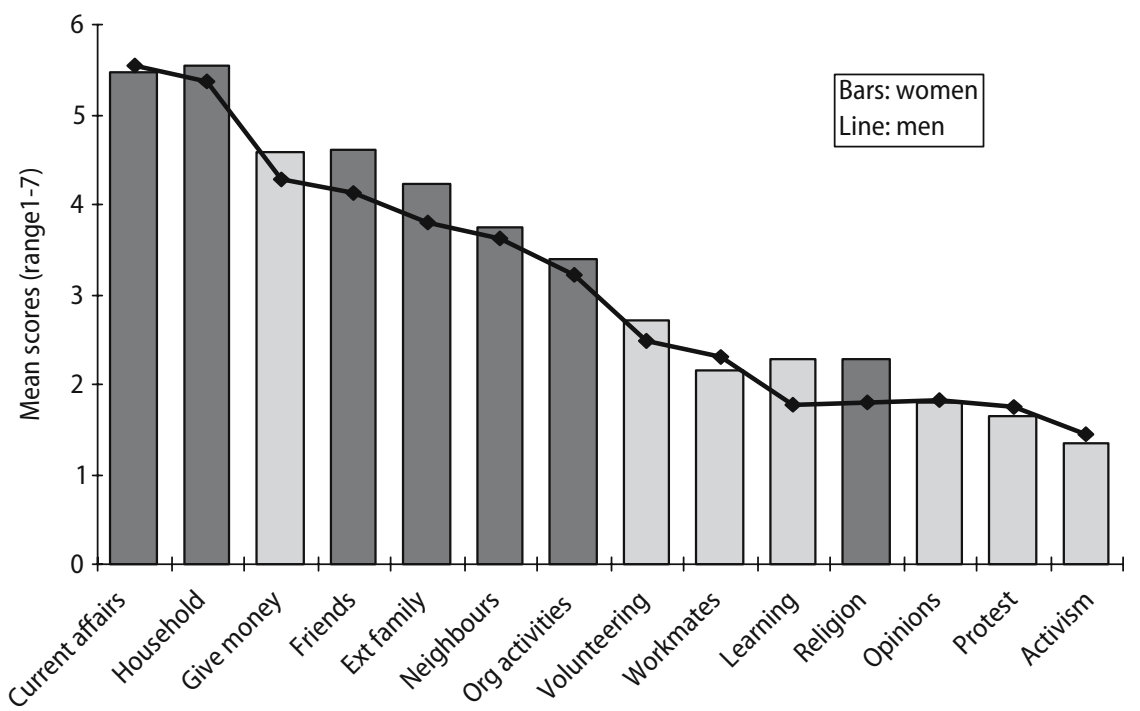

Sixty-six percent of participants agreed that "most people can be trusted", with women (70\%) significantly more likely than were men $(62 \%)$ to endorse this item $(F=6.22, d f(1), P<0.01)$. Consistent with the single item measure of trust, mean scores on the OTI indicated that participants tended to trust rather than not to trust other people, with women $\left(M=5.16, S_{\mathrm{x}}=\right.$ .94) reporting significantly greater trust in others than did men (men $M=4.91, S_{\mathrm{x}}=1.00, F=16.31, d f(1)$, $P<0.0001$ ). Women also reported slightly higher levels of optimism than did men (women $M=5.07, S_{\mathrm{x}}=1.01$, men $\left.M=4.87, S_{\mathrm{x}}=1.00 ; F=9.57, d f(1), P<0.01\right)$.

\section{Cluster analysis: four types of participators}

Criterion statistics for the agglomeration schedules and the ratios of change for both criteria indicated cut- offs at four clusters (see website). The four clusters included two larger and two smaller groupings, which differed on all socio-demographic characteristics (Table 3).

At 41 years old, men, Australian-born, non-Indigenous people, those in full-time paid work, those who did not hold a health care card, and those who had children, particularly older children, were overrepresented in Cluster 1. In cluster 2, the smallest cluster, with a mean age of 60 years, those with professional qualifications and, to some extent, certificates, diplomas or degrees, were over-represented. So, too, were those not in paid work and those who did not have preschoolers or primary school-aged children living with them. Women, people in parttime paid work, and people with preschoolers and primary school-aged children were over-represented in Cluster 3, the second-smallest cluster. At 42 years

Table 2 Mean scores and standard deviations for age, personal social cohesion and psychological distress (higher scores indicate greater cohesion and worse distress)

\begin{tabular}{|c|c|c|c|c|c|c|c|c|c|c|}
\hline & \multicolumn{2}{|c|}{$\begin{array}{l}\text { Cluster 1: Busy } \\
\text { working parents }\end{array}$} & \multicolumn{2}{|c|}{$\begin{array}{l}\text { Cluster 2: Social } \\
\text { Capital Elites }\end{array}$} & \multicolumn{2}{|c|}{$\begin{array}{l}\text { Cluster 3: Excluded } \\
\text { participators }\end{array}$} & \multicolumn{2}{|c|}{$\begin{array}{l}\text { Cluster 4: Aging, } \\
\text { participating less }\end{array}$} & \multicolumn{2}{|c|}{ Whole sample } \\
\hline & Mean & $S_{x}$ & Mean & $S_{x}$ & Mean & $\mathrm{S}_{\mathrm{x}}$ & Mean & $S_{x}$ & Mean & $S_{x}$ \\
\hline Age in years & 40.47 & 11.30 & $59.87^{* * * 9}$ & 14.00 & 42.08 & 12.90 & $69.24^{* * * 9}$ & 14.21 & 52.78 & 18.24 \\
\hline \multicolumn{11}{|l|}{ Personal social cohesion } \\
\hline Universalism (altruistic values) & 5.93 & 0.78 & $6.15^{* a, g}$ & 0.74 & 5.98 & 0.82 & 5.98 & 0.82 & 5.99 & 0.80 \\
\hline Sense of belonging & 8.49 & 2.02 & $8.76^{* * * c, g}$ & 1.93 & $7.28^{\# h}$ & 2.75 & $7.96^{\# h}$ & 2.52 & 8.13 & 2.37 \\
\hline Social trust (weighted composite) & 5.08 & 0.92 & $5.27^{* * * b, g}$ & 1.00 & $4.75^{\# \# \mathrm{~h}}$ & 1.00 & 5.06 & 0.98 & 5.04 & 0.98 \\
\hline Reciprocity & $0.78^{\#}$ & 0.42 & $0.84^{* \mathrm{~b}, \mathrm{~g}}$ & 0.37 & $0.71^{\# h}$ & 0.46 & 0.83 & 0.38 & 0.79 & 0.41 \\
\hline Optimism & $5.08^{* *}$ & 0.94 & $5.26^{* * * c, g}$ & 0.97 & $4.76^{\# \# \mathrm{~d}, \mathrm{~h}}$ & 1.16 & 4.83 & 0.96 & 4.97 & 1.01 \\
\hline \multicolumn{11}{|l|}{ Psychological wellbeing } \\
\hline Psychological distress (K10) & $17.38^{\# \# \#, \mathrm{~h}}$ & 5.41 & $17.38^{\# \# \#, \mathrm{~h}}$ & 6.28 & $20.24^{* *} \mathrm{~g}$ & 6.81 & 18.15 & 6.12 & 18.18 & 6.15 \\
\hline
\end{tabular}

${ }^{a}$ Mean is significantly higher than that of Cluster 1 only

${ }^{\mathrm{b}}$ Mean is significantly higher than that of Cluster 3 only

${ }^{c}$ Mean is significantly higher than those of Clusters 3 and 4 only

${ }^{\mathrm{d}}$ Mean is significantly higher than those of Clusters 1 and 3 only

eMean is significantly higher than that of Cluster 2 only

${ }^{f} M$ Mean is significantly lower than that of Cluster 3 only

${ }^{9}$ Mean is significantly higher than the next highest mean, ${ }^{*} P<0.05,{ }^{* *} P<0.01,{ }^{* * *} P<0.001$

${ }^{\mathrm{h}}$ Mean is significantly lower than the next lowest mean, ${ }^{\#} P<0.05$, ${ }^{\# \#} P<0.01$, \#\#\# $P<0.001$ 
Table 3 Distributions of respondents in each cluster by socio-demographic characteristics

\begin{tabular}{|c|c|c|c|c|}
\hline & $\begin{array}{l}\text { Cluster 1: Busy Working } \\
\text { Parents }(N=319,33.1 \%)\end{array}$ & $\begin{array}{l}\text { Cluster 2: Social capital } \\
\text { elites ( } N=161,16.7 \%)\end{array}$ & $\begin{array}{l}\text { Cluster 3: Excluded } \\
\text { participators } \\
(N=190,19.7 \%)\end{array}$ & $\begin{array}{l}\text { Cluster 4: Aging, } \\
\text { participating less } \\
(N=293,30.4 \%)\end{array}$ \\
\hline \multicolumn{5}{|l|}{ Sex } \\
\hline Female & 130 & 93 & $145^{* * *}$ & 132 \\
\hline Male & $189 * * *$ & 68 & 45 & 161 \\
\hline \multicolumn{5}{|l|}{ Ethnicity } \\
\hline Indigenous Australian & 16 & 21 & 9 & $38^{*}$ \\
\hline Overseas born & 23 & 22 & 22 & $69^{* * *}$ \\
\hline Australian born non-Indigenous & $280^{* * *}$ & 118 & 159 & 186 \\
\hline \multicolumn{5}{|l|}{ Education } \\
\hline High school or less & 141 & 51 & 101 & $190^{* * *}$ \\
\hline Certificate, diploma, degree & $147^{* * *}$ & $71^{\#}$ & 58 & 72 \\
\hline Professional, higher degree & 31 & $39 * * *$ & 31 & 31 \\
\hline \multicolumn{5}{|l|}{ Paid work } \\
\hline Not in paid work & 2 & $125^{* * *}$ & 78 & $291^{* * *}$ \\
\hline Part-time paid work & 57 & 8 & $94^{* * *}$ & 2 \\
\hline Full-time paid work & $260^{* * *}$ & 28 & 18 & 0 \\
\hline \multicolumn{5}{|l|}{ Health care card } \\
\hline No & $276^{* * *}$ & 78 & 80 & 35 \\
\hline Yes & 43 & 83 & 110 & $258^{* * *}$ \\
\hline \multicolumn{5}{|l|}{ Preschool children (under 5 years) } \\
\hline No & 273 & $155^{*}$ & 144 & $292^{* * *}$ \\
\hline Yes & $46^{*}$ & 6 & $46^{* * *}$ & 1 \\
\hline \multicolumn{5}{|l|}{ Primary school children (6-2 years) } \\
\hline No & 254 & $155^{* * *}$ & 128 & $293^{* * *}$ \\
\hline Yes & $65^{* *}$ & 6 & $62^{* * *}$ & 0 \\
\hline \multicolumn{5}{|l|}{ High school children (13-18 years) } \\
\hline No & 253 & 151 & 159 & $293 * * *$ \\
\hline Yes & $66^{* * *}$ & 10 & 31 & 0 \\
\hline
\end{tabular}

Obtained value is significantly larger than expected value based on $\chi^{2}$ distributions, where ${ }^{*} P<0.01,{ }^{* *} P<0.001,{ }^{* * *} P<0.0001$. All estimates were based on adjusted standardised residuals (adjusted for group sizes) $>3$

old, they tended to hold health care cards. With a mean age of 70 years, only one respondent in Cluster 4 , the second largest cluster, had a child living at home. Indigenous Australians were slightly overrepresented in the cluster, which also contained an over-representation of people born overseas, with high school education or less, not in paid work and holding a health care card.

\section{Clusters and community participation}

Cluster centroids and standard deviations for types of, and perceptions about, participation are presented in Table 1 . Members of cluster 1 reported average levels of most types of participation, except for elevated levels of contact with household members and social contact with workmates, and low levels of contact with neighbours. Members of cluster 2 reported the highest levels-except for contact with household members-of all types of participation. They were the only cluster to report elevated involvement in most types of civic engagement and all types of political participation. They reported the greatest breadth of participation across the Big 7 types, the greatest enjoyment of participation, and the lowest perception of participating too little. They also reported the highest levels of participating too much (though, with a mean score of 0.39 out of a possible range of $0-7$, this was rare).

Members of cluster 3 reported elevated levels of contact with household members, of participating too little, and of not enjoying participating. They reported low levels-often the lowest-of all types of participation. This included most of the Big 7 types of participation (contact with extended family, friends, neighbours, organised community activities, active interest in current affairs). They also reported by far the lowest levels of breadth of participation and of enjoyment of participating. Cluster 4 was also a low participation group, with low levels of contact with household members, social contact with workmates, ongoing informal learning, organised community activities and political protest. They reported the lowest levels of participating too much.

\section{Clusters and social cohesion}

Mean scores and standard deviations for measures of social cohesion by cluster are presented in Table 2 . Members of Cluster 1 reported the same level of acceptance of universalism as did Clusters 3 and 4, but slightly less than did Cluster 2. Their sense of 
belonging was lower than, but not significantly different from that of Cluster 2, but it was significantly higher than that of the other two clusters. They reported the same levels of trust as did Cluster 4, significantly less trust than did Cluster 2 and more than Cluster 3. Members of Cluster 1 reported the third lowest reciprocity, higher only than that of Cluster 3, but the second highest level of optimism, lower only than that of Cluster 2. Members of Cluster 2 reported the highest levels of universalism, sense of belonging, social trust, reciprocity and optimism of all the clusters. Members of Cluster 3 reported the lowest levels of sense of belonging, social trust, reciprocity and optimism of all the clusters and the same level of acceptance of universalism as did Clusters 1 and 3 . Members of Cluster 4 reported the same level of acceptance of universalism as did Clusters 3 and 4, but slightly less than did Cluster 2. They reported the second lowest sense of belonging. Their levels of social trust and optimism were also the second lowest of all the clusters, equal to those of Cluster 1 . They reported the highest level of reciprocity, equal to that of Cluster 2.

\section{Clusters and psychological distress}

Levels of psychological distress by cluster are presented in Table 2. Clusters 1 and 2 did not differ in their levels of distress, which were low relative to the sample mean and significantly lower than those of the other clusters. Members of cluster 3 reported high levels of distress relative to the sample mean and greater distress than all the other clusters. Members of cluster 4 reported average levels of distress relative to the whole sample, and significantly higher than those of Clusters 1 and 2.

\section{Integrating the cluster results: profiles of participators}

Busy working parents: Aged around 41 years, men were over-represented in Cluster 1 , as were nonIndigenous Australian-born young to mid-aged parents of older children. Almost all were in full-time paid work, perhaps explaining their low levels of social contact with neighbours. Many had postschool education and few were experiencing financial hardship. While elevated levels of community participation were limited to social contact with members of their households and workmates, they tended to enjoy participating and to say they participated too little. They had average to high levels of social cohesion, reporting the second highest levels of universalism, sense of belonging, social trust and optimism. Only their levels of reciprocity were low, the third lowest of any cluster. Together with members of Cluster 2, they reported the lowest levels of distress. In their early mid-life and with participation focused on responsibilities to paid work and children, these respondents are described as "busy working parents".

Social capital elite: At around 60 years old, the men and women of Cluster 2 were predominantly in retirement and few had children still living at home. Highly educated, they reported very high levels of all types of community participation (including social contact with workmates, even though only two cluster members were in paid work), along with very high breadth of participation, enjoyment of participating and perceptions of participating enough (perhaps occasionally too much). They were the only cluster that reported taking part in all types of civic engagement (most notably volunteering) and all types of political participation. Of all the clusters, they reported the highest levels of universalism, sense of belonging, social trust, reciprocity and optimism. With their very high levels of community participation, enjoyable and sufficient participation, strong sense of personal social cohesion and, together with busy working parents, the lowest levels of distress, these respondents invested heavily in social capital and derived the greatest return from their investment. They are named the "social capital elite".

Excluded participators: Like busy working parents, at around 42 years old, members of Cluster 3 were in early mid-life. The large majority were women. With those in part-time paid work over-represented in Cluster 3, and very few in full-time paid work, most were holders of health care cards, indicating elevated rates of poverty. Parents of preschool and primary school aged children were over-represented. Members of Cluster 3 spent more time with members of their households than did the other clusters but had the lowest levels of all other types of participation (except for social contact with workmates), particularly the Big 7 that are linked to mental health benefits. Their perceptions about participation were complex. They did not enjoy participating, with the lowest levels of enjoying participating backed up by the highest levels of not enjoying it. They reported the strongest perceptions of participating too little, yet also stated that they participated too much. Though they reported the same level of acceptance of universalism as did Clusters 1 and 4, they had the lowest levels of sense of belonging, social trust, reciprocity and optimism of all the clusters. They reported the highest levels of distress. With young children, struggling financially and psychologically, social contact largely limited to their households and very low levels of social cohesion, Members of Cluster 3 seemed simultaneously overwhelmed by family responsibilities, cut off from other aspects of community life and lacking a sense of cohesion, or connectedness, to their community. These respondents are called "excluded participators".

Ageing, participating less: At around 70 years old, members of Cluster 4 were the oldest group, had no children living at home and contained more overseas- 
born and Indigenous Australians than did the other clusters. With the large majority having high school or less education, they had completed the least education of any group. Being in retirement and eligible for age-related government income support, most held health care cards. While their levels and experiences of participation were not as poor as those of the excluded participators, members of cluster 4 reported low levels of contact with household members and workmates, ongoing learning and participation in organised community activities and considerably less breadth of participation than that reported by the social capital elite, their juniors by only a decade. They did, however, report relatively high levels of contact with neighbours.

Cluster 4's perceptions about their participation were fairly positive. They reported average levels of participating too little and of enjoying participating, very low levels of not enjoying participating and were the least likely to state that they participated too much. They reported average to poor social cohesion, with average levels of universalism and social trust, compared with the sample as a whole, and the second lowest sense of belonging and optimism of any cluster. However, perhaps because of their elevated contact with neighbours, they reported the joint highest level of reciprocity, equal to that of the social capital elite. Members of Cluster 4 reported the second highest levels of distress. With modest to low levels of participation and a sense of not participating enough, but spending time with neighbours, enjoying participating and having a strong sense of reciprocity, members of Cluster 4 seemed positively oriented towards, but somewhat deprived of, community participation. Increasing age and unfavourable financial circumstances were perhaps driving this situation and contributing to their poor sense of belonging and optimism. These respondents are named "ageing, participating less".

\section{Evaluating the adequacy of the cluster solution}

Reducing this dataset $(N=963)$ to four reasonably homogenous categories represents a substantial summarising of the data, meeting the criterion of parsimony. The solution produced two larger and two smaller clusters, each differing substantially in sociodemographic characteristics, community participation, social cohesion and psychological distress. These varied meaningfully from one another, with lower reported community participation and social cohesion found among those who were (1) older, (2) experiencing socio-demographic disadvantage and, to some extent, (3) time-pressured. These distinctions reflected recognisable types of people in the community, indicating consistency with the criterion of meaningfulness. With implications for further research and for program and policy development (discussed below), the solution was scientifically useful.
A four-cluster solution was also consistent with the statistical criteria.

\section{Discussion}

The aims of this study were to group and describe members of a socio-economically disadvantaged rural region according to patterns of community participation, report on their levels of social cohesion and psychological distress and reflect on service delivery implications. The cluster analysis delivered a four-cluster solution which met the evaluation criteria: the clusters were internally coherent and differed systematically from each other in terms of sociodemographic characteristics, patterns of and perceptions about participation, levels of social cohesion and psychological distress. The clusters were consistent with the findings of other research, particularly with those of another Australian study of participation and health [5] in which levels of participation varied between the sexes, types of participation and socioeconomic circumstances and in which low levels of participation and elevated psychiatric morbidity were found among the most disadvantaged (the last consistent with Australian norms, [6]).

\section{Social capital and gender, socio-economic circumstances and life course development}

Sex differences in the present study were notable, suggesting a gendered relationship between social capital and mental health: women attained significantly higher scores than did men on most forms of participation, including six of the Big 7 types, and in overall levels of personal social cohesion (universalism, generalised reciprocity, social trust and optimism). This suggests that women have higher overall levels of social capital, which is considered protective against mental health problems. Yet, contradictorily (but consistent with Australian norms, [6]), they reported higher levels of psychiatric morbidity.

The present analysis suggests that women vary considerably and systematically in their levels of social capital, with socio-economic disadvantage perhaps explaining the seemingly anomalous finding. In contrast to other women in the study, the social capital deprivation of excluded participators, the large majority of whom were women and/or socioeconomically disadvantaged, was notable, as were their high levels of psychological distress. Their complex experience of participation is explained perhaps by other research describing the sometimes onerous obligations associated with participation [21], the role strain it can involve, particularly for poorly resourced women [29], and its potential, therefore, to represent a liability for some people [2]. At the other extreme of the advantage/disadvantage 
spectrum, and also consistent with this literature, socio-economic advantage was prominent among the social capital elite, whose experience of participation was full and enjoyable. Their privileged position with respect to participation (and their near sole responsibility for volunteering and political participation in the community) and perceptions about participation were matched by their high levels of social cohesion and good mental health.

While gender and socio-economic deprivation or privilege might explain membership of the most disadvantaged and advantaged clusters, life course development might explain membership of the remaining clusters: busy working parents and ageing, participating less. In terms of social capital and mental health, these types occupied the middle ground between the extremes marked by the excluded participators and the social capital elite. With postsecondary education, very high employment, little poverty and fairly high levels of social cohesion in the context of a socio-economically disadvantaged rural region, busy working parents were not disadvantaged but time-pressured. In early mid-age, with children to care for and full-time paid work, they would not have time for extensive community participation beyond fulfilling social obligations at home and at work.

Ageing, participating less group members also showed characteristics typical of their life stage (for cluster analyses providing detailed age-related profiles using a large, nationally representative Australian study, see $[11,12])$. Ageing is often accompanied by reliance on age-related government income support, an "empty nest", widowhood and increasing health concerns, including lower mobility, the last two of which featured in comments written by older respondents in their questionnaires. Lack of money, living alone and being unable to get around can all limit participation. Relatively high levels of contact with neighbours (a form of social contact that would fall within many group members' financial and physical capacity), high generalised reciprocity, enjoyment of participation and perceptions about participating too little certainly suggest a positive orientation to participation and an inclination to participate more. This group's fairly poor sense of belonging, trust, optimism and mental health were perhaps a natural response to an understandable but avoidable age-related decrease in participation.

\section{Policy implications}

At least three policy and service delivery implications emerge from this study. First, participation is amenable to intervention in a way that social cohesion is not: compared with providing, for example, psychiatric services to address individual issues of trust, it is relatively efficient, inexpensive and administratively straightforward to increase appropriate types of community participation. Services as simple as transport for people in need, particularly in rural and remote locations, could substantially improve participation. In addition to potential benefits to mental health, increased participation could be expected to raise levels of social capital and, consequently, contribute to decreases in other health and social problems.

Second, only one group, the social capital elite, reported engaging substantially across almost all types of participation. This finding is consistent with other research that has claimed that society's elites engage more deeply and broadly than do other groups, and that they assume leadership roles and exercise the most influence, particularly through their civic and political participation [24, 40, 49]. Though, according to these studies, elites have by far the greatest say in their communities, with their distinct and advantaged socio-demographic and participation characteristics, the voice of elites may not always reflect the needs or views of all groups. Policy-makers may use the findings of studies such as this to more accurately identify a broader range of stakeholder groupings, including those with limited or no voice, and to consider how to respond to patterns of inclusion and exclusion that sit behind their perspectives: the imperative to confront issues of elite power and influence has been directly implicated in the use of community participation and capacity-building as a health promotion strategy [53].

Third, targeting services to those that most need them and tailoring them to fit is a perennial public policy challenge. Typically, health services are accessed by those who least need them, but who have the resources to find and take advantage of them [42], while those experiencing ill-health [14] and other disadvantage $[19,51]$ miss out. This is an issue of social justice which social policy must confront [53]. It also has practical implications for participation-based health promotion, for which the present study indicates potential strategies. The key point is that, to be effective, interventions need to be differentiated and adapted to the circumstances of intended recipients. This requires accurate information about target groups (types of people according to characteristics of interest), the involvement of all appropriate government agencies and the participation of policy-sensitive researchers in the policymaking process (e.g. [13]). Related to this point, the social capital elite and the excluded participators represented the extreme ends of the dis/advantage spectrum, comprising the two smallest groups and, respectively, those most and least likely to access participation-based health promotion activities. The busy working parents and aging, participating less groups occupied the middle ground and represented the bulk of respondents. These distributions of respondents also have implications for policy development and program delivery. 
Greater coverage and more tailoring of public transport, and more daytime neighbourhood-based activities, might assist those who are ageing, participating less. But they are unlikely to be useful interventions for busy working parents because they do not need assistance with transport and are away from home at work. Types of participation that take account of their family and work responsibilities, such as workplace-based family-friendly social events, might be more helpful. The most disadvantaged group, the excluded participators, are not the only group that has needs or would benefit from participation-enhancing interventions, but they face complex circumstances. Like busy working parents, they are heavily committed to family and, to a lesser extent, to paid work, while, like the ageing, participating less group, they have limited financial resources. In addition, they have high levels of distress and complicated perceptions about participation, not enjoying it, and reporting they participate too much and too little. Addressing barriers to enjoyable and sufficient participation among excluded participators would require further investigation of the reasons behind their very low levels of participation, and their negative perceptions about it.

\section{Limitations of the study}

General limitations of the Eurobodalla Study, from which data for the present study were drawn, have been discussed elsewhere $[9,11]$. While the analytic approach for the present study was strong and most measures well-validated and appropriate for use with this population, the measures of perceptions of participation exhibited mainly inadequate internal consistency. These measures were experimental and require further development. Nevertheless, their use made an important contribution to the cluster solution and associated analyses, suggesting that perceptions are an important part of understanding types of people in terms of patterns of participation and access to social capital.

This study focused on a socio-economically disadvantaged rural Australian population and the types of participators identified might be particular not just to this sample but to this type of population. While respondents wrote informative comments on their questionnaires, the lack of purposive qualitative data in this study limits understanding [2] of the barriers and facilitators to participation among lower participation groups, particularly the excluded participators. This understanding is essential to effective tailoring of services for poorly connected people [33] and for people with intransigent problems [28, 42]. In addition, with such detailed data on participation, it was not possible to collect extensive socio-demographic data, also needed to describe the profiles more fully.

\section{Conclusions}

Despite these limitations, the goals of the present study were not to propose that there are four, or these four, types of participators in communities, or to define them comprehensively, but to demonstrate that there is value in exploring statistically how people might be grouped in terms of systematically varying patterns of participation in order to better target participation-related mental health promotion strategies. This paper has shown how a careful analysis of community participation, comprehensively defined and measured, and of perceptions about participation, combined with a wide range of elements of social cohesion and key socio-demographic characteristics, may shed light on important and fundamental differences among sub-groups within communities. This, in turn, suggests how and whether different groups might respond to the use of increased community participation as a mental health promotion strategy and points to some of the barriers that might have to be overcome for such strategies to be successful.

\section{References}

1. Adlaf EM, Ialomiteanu A (2000) Prevalence of problem gambling in adolescents: findings form the 1999 Ontario Student Drug Use Survey. Can J Psychiatry 45(8):752-755

2. Almedom AM (2005) Social capital and mental health: an interdisciplinary review of primary evidence. Soc Sci Med 61(5):943-964

3. Alston M (2002) Social capital in rural Australia. Rural Soc 12(2):93-104

4. Andrews G, Slade T (2001) Interpreting scores on the Kessler Psychological Distress Scale (K10). Aust N Z J Public Health 25(6):494-497

5. Baum FE, Bush RA, Modra CC, Murray CJ, Cox EM, Alexander KM, Potter RC (2000) Epidemiology of participation: an Australian community study. J Epidemiol Community Health 54(6):414-423

6. Begg S, Vos T, Barker B, Stevenson C, Stanley L, Lopez A (2003) The burden of disease and injury in Australia 2003. Australian Institute of Health and Welfare, Canberra

7. Berry HL, Rickwood DJ (2000) Measuring social capital at the individual level: personal social capital, values and psychological distress. Int J Ment Health Promot 2(3):35-44

8. Berry HL, Rodgers B (2003) Trust and distress in three generations of rural Australians. Australas Psychiatry 11(S):S131S137

9. Berry HL, Rodgers B, Dear KBG (2007) Preliminary development and validation of an Australian community participation questionnaire: types of participation and associations with distress in a coastal community. Soc Sci Med 64(8):1719-1737

10. Berry HL, Shipley M (2007) Longing to belong: personal social capital and psychological distress in a coastal Australian region. The Australian National University, Canberra

11. Berry HL, Butterworth P, Caldwell TM, Rodgers B (2008). Contemporary Australian archetypes: different types of people, different needs, social policy Research Paper No. 32. Australian Government Department of Families, Community Services and Indigenous Affairs, Canberra

12. Berry HL (2007) Twelve types of Australians and their socioeconomic, psychosocial and health characteristics, Social Policy Research Papers. Australian Government Department of Families Community Services and Indigenous Affairs, Canberra 
13. Brownson RC, Royer C, Ewing R, McBride TD (2006) Researchers and policymakers: travelers in parallel universes. Am J Prev Med 30(2):164-172

14. Buetow SA, Kerse NM (2001) Does reported health promotion activity neglect people with ill-health? Health Promot Int 16(1):73-78

15. Cohen S, Mermelstein R, Kamarck T, Hoberman HM (1985) Interpersonal support evaluation list. In: Sarason GS, Sarason BR (eds) Social support: theory, research and application. Martinus Nijhoff, Washington DC

16. Cummins LL, Bromiley $P$ (1996) The organizational trust inventory (OTI): development and validation. In: Kramer RM, Tyler TR (eds) Trust in organizations: frontiers of theory and research. Sage Publications, California, pp 302-330

17. De Silva MJ, McKenzie K, Harpham T, Huttly SRA (2005) Social capital and mental illness: a systematic review. J Epidemiol Community Health 59(8):619-627

18. De Silva MJ, Huttly SR, Harpham T, Kenward MG (2007) Social capital and mental health: a comparative analysis of four low income countries. Soc Sci Med 64(1):5-20

19. Eckert KA, Taylor AW, Wilkinson D (2004) Does health service utilisation vary by remoteness? South Australian population data and the accessibility and remoteness index of Australia. Aust N Z J Public Health 28(5):426-432

20. Farr J (2004) Social capital: a conceptual history. Polit Theory $32(1): 6-33$

21. Ferlander S (2007) The importance of different forms of social capital for health. Acta Sociol 50(2):115-128

22. Harpham T, Grant E, Thomas E (2002) Measuring social capital within health surveys: key issues. Health Policy Plan 17(1):106-111

23. Hendry LB, Reid M (2000) Social relationships and health: the meaning of social connectedness and how it relates to health concerns for rural Scottish adolescents. J Adolesc 23(6):705719

24. Heying $\mathrm{CH}$ (1997) Civic elites and corporate dislocation: an alternative explanation for declining civic engagement. Am Behav Sci 40:657-668

25. Hyyppa MT, Maki J (2003) Social participation and health in a community rich in stock of social capital. Health Educ Res 18(6):770-779

26. Iacono T, Davis R, Humphreys J, Chandler N (2003) GP and support people's concerns and priorities for meeting the health care needs of individuals with developmental disabilities: a metropolitan and non-metropolitan comparison. J Intellect Dev Disabil 28(4):353-368

27. Inglehart R, et al. (1997) World values surveys: cumulative file for the first three waves. ICPSR Survey Data Archive, Ann Arbor

28. Juvonen-Posti P, Kallanranta T, Eksyma SL, Piirainen K, Keinanen-Kiukaanniemi S (2002) Into work, through tailored paths: a two-year follow-up of the return-to-work rehabilitation and re-employment project. Int J Rehabil Res 25(4):313-330

29. Kawachi I, Berkman LF (2001) Social ties and mental health. J Urban Health Bull N Y Acad Med 78(3):458-467

30. Kessler RC, Andrews G, Colpe LJ, Hiripi E, Mroczek DK, Normand S-LT, Walters EE, Zaslavsky AM (2002) Short screening scales to monitor population prevalences and trends in nonspecific psychological distress. Psychol Med 32(6):959-976

31. Kuchukeeva A, John O’Loughlin J (2003) Civic engagement and democratic consolidation in Kyrgyzstan. Eurasian Geogr Econ 44(8):557-587

32. Kulkarni R, Kent J, Bennett M (2001) A strategy to promote mental well-being in Berkshire 2001-2010: Berkshire health promotion

33. Lee RM, Draper M, Lee S (2001) Social connectedness, dysfunctional interpersonal behaviors, and psychological distress: testing a mediator model. J Couns Psychol 48(3):310-318
34. Mansyur C, Amick BC, Harrist RB, Franzini L (2008) Social capital, income inequality, and self-rated health in 45 countries. Soc Sci Med 66(1):43-56

35. McAllister I (1998) Civic education and political knowledge in Australia. Aust J Polit Sci 33(1):7-23

36. Mitchell AD, Bossert TJ (2007) Measuring dimensions of social capital: evidence from surveys in poor communities in Nicaragua. Soc Sci Med 64(1):50-63

37. Moore S, Haines V, Hawe P, Shiell A (2006) Lost in translation: a genealogy of the social capital concept in public health. J Epidemiol Community Health 60(8):729-734

38. Murray G, Judd F, Jackson H, Fraser C, Komiti A, Hodgins G, Pattison P, Humphreys J, Robins G (2004) Rurality and mental health: the role of accessibility. Aust N Z J Psychiatry 38(8):629634

39. Prince M, Harwood R, Thomas A, Mann A (1998) A prospective population-based cohort study of the effects of disablement and social milieu on the onset and maintenance of late-life depression. The Gospel Oak Project VII. Psychol Med 28:337-350

40. Putnam RD (1995) Bowling alone: America's declining social capital. J Democracy 6:65-78

41. Putnam RD (2000) Bowling alone: the collapse and revival of American Community. New York: Simon \& Schuster

42. Quine S, Kendig H, Russell C, Touchard D (2004) Health promotion for socially disadvantaged groups: The case of homeless older men in Australia. Health Promotion Int 19(2):157-165

43. Rich P (1999) American voluntarism, social capital, and political culture. The Annals 565(1):15-34

44. Riise T, Lund A (2001) Prognostic factors in major depression: a long-term follow-up study of 323 patients. J Affect Disord 65(3):297-306

45. Sartorius N (2001) The economic and social burden of depression. J Clin Psychiatry 62(Suppl 15):8-11

46. Sartorius N (2003) Social capital and mental health. Curr Opin Psychiatry 16(Suppl 2):S101-S105

47. Schudson M (1996) What if civic life didn't die? Am Prospect 25:17-20

48. Schwarz SH (1992) Universals in the content and structure of values: theoretical advances and empirical tests. In: Zanna MP (ed) Advances in experimental social psychology. Academic, San Diego, pp 1-65

49. Skocpol $\mathrm{T}$ (2000) The Tocqueville problem: civic initiative in American Democracy. Teorija in Praksa 37(6):1132-1152

50. Smidt C (1999) Religion and civic engagement: a comparative analysis. Annals 565(1):176-192

51. Turrell G, Oldenburg BF, Harris E, Jolley D (2004) Utilisation of general practitioner services by socio-economic disadvantage and geographic remoteness. Aust N Z J Public Health 28(2):152-158

52. Uslaner EM, Conley RS (2003) Civic engagement and particularized trust: the ties that bind people to their ethnic communities. Am Polit Res 31(4):331-360

53. Wakefield SEL, Poland B (2005) Family, friend or foe? Critical reflections on the relevance and role of social capital in health promotion and community development. Soc Sci Med 60(12):2819-2832

54. Waring T, Hazell T, Hazell P, Adams J (2000) Youth mental health promotion in the Hunter region. Aust N Z J Psychiatry 34:579-585

55. Whitley R, McKenzie K (2005) Social capital and psychiatry: review of the literature. Harv Rev Psychiatry 13(2):71-84

56. Young AF, Dobson AJ (2003) The decline in bulk-billing and increase in out-of-pocket costs for general practice consultations in rural areas of Australia, 1995-2001. Med J Aust $178(3): 122-126$ 